\title{
DISPOSITIVO ERGONÔMICO DE IÇAMENTO DE RODA FERROVIÁRIA POR SISTEMA DE FIXAÇÃO UNIVERSAL PARA TRANSPORTE E MOVIMENTAÇÃO DE CARGA AÉREA.
}

\author{
V. H. P. Paiva ${ }^{1,}$; D. J. R. Marques ${ }^{1}$; R. A. Moura $^{2}$ \\ 1 Universidade de Taubaté - UNITAU. \\ Rua Daniel Danelli, s/n - Vila Nossa Senhora das Graças, Taubaté/SP, \\ CEP: 12060-440, Brasil. \\ Telefone: (12) 3622-4005 \\ 2. Faculdade de Tecnologia de São José dos Campos - Professor Jessen Vidal \\ Av. Cesare Mansueto Giulio Lattes, 1350 - Eugênio de Melo, São José dos Campos/SP, \\ CEP.: 12247-014, Brasil. \\ Telefone: (12) 3905-2423 \\ *vitorhugopazini@ hotmail.com
}

\begin{abstract}
RESUMO: Este projeto busca solucionar as limitações de um equipamento de içamento de rodas ferroviárias no processo de usinagem, devido à variedade em sua geometria, diâmetros e pesos, como também os problemas ergonômicos causados pelo método de manuseio utilizado nas garras convencionais, sendo necessário aplicar uma determina força para realizar sua fixação. Desenvolver uma haste para o usuário trabalhar a uma distância suficiente para que não ocorra algum incidente, caso não seja fixado corretamente na roda ferroviária. Para validar o dispositivo foi realizado um estudo de elementos finitos, a fim de averiguar sua resistência estrutural, de modo a suportar os esforços solicitados durante a operação na qual é empregado.
\end{abstract}

PALAVRAS-CHAVE: Garras; sistema de içamento; roda ferroviária.

ABSTRACT: This project seeks to solve the limitations of a railway wheel lifting equipment in the machining process, due to the variety in its geometry, diameters and weights, as well as the ergonomic problems caused by the handling method used in the clamping jaws, being necessary to apply a determined force to make its fixation. Develop a rod for the user to work at a sufficient distance so that no incident occurs if it is not fixed correctly on the rail. In order to validate the device, a finite element study was carried out in order to verify its structural strength in order to withstand the stresses required during the operation in which it is used.

KEYWORDS: Clamp; lifting system; railway wheel.

\section{INTRODUÇÃO}

O deslocamento de qualquer tipo de carga representa riscos, por ser uma atividade perigosa, que trazem consequências graves, de modo geral podem ser representadas pela queda da própria carga ou do veiculo transportador, atingindo a carga, o veiculo, pessoas, o patrimônio dessas e gerando muitos transtornos.

Há outros fatores que podem aumentar os riscos, como os tipos de dimensões e geometrias das cargas, dos pesos, dos equipamentos envolvidos, trajeto a ser realizado e quantidade de pessoas para executa-la. 
Inicialmente o transporte ou movimentação de carga estava relacionado à atividade humana direta ou indireta através de dois meios:

$\checkmark$ Empregando o esforço físico humano;

$\checkmark$ Utilizando o esforço de animais de tração.

Com a evolução tecnológica e aumento das dimensões das cargas e das dificuldades dos transportes, o homem passou a desenvolver dispositivos especiais, como torres, polias, carretilhas, e outros meios, até chegar aos guindastes com alta capacidade para elevar cargas (NAVARRO, 2019).

Neste viés houve também evolução nas empresas do seguimento ferroviário, especificamente da produção de rodas e eixos, utilizam equipamentos de içamento de carga por meio de talhas elétricas com dispositivos de fixações especiais, para alojar e retirar sua matéria prima dos equipamentos de usinagem com objetivo de garantir segurança dos danos físicos e patrimoniais bem como toda a realidade da fabricação.

\subsection{Definição do problema}

Por se tratar de um projeto específico, de transporte aéreo de carga, buscou-se identificar os principais métodos já existentes nesta área e propor melhorias em cima das limitações do manuseio de rodas ferroviárias no setor de usinagem. Elaborando um sistema de fixação universal para travamento e içamento de vários modelos de rodas ferroviárias, diâmetros, geometria e pesos sendo acopladas em um dispositivo ergonômico de içamento de roda ferroviária por sistema de fixação universal com comando elétrico.

Atualmente os modelos de garrincha (gancho de fixação), não suportam e não flexibilizam pegar a roda em ambos os frisos, ou seja, friso para cima e para baixo, conforme demonstrado na Figura 1. A mesma figura apresenta croqui com as principais partes da roda e seus detalhes.

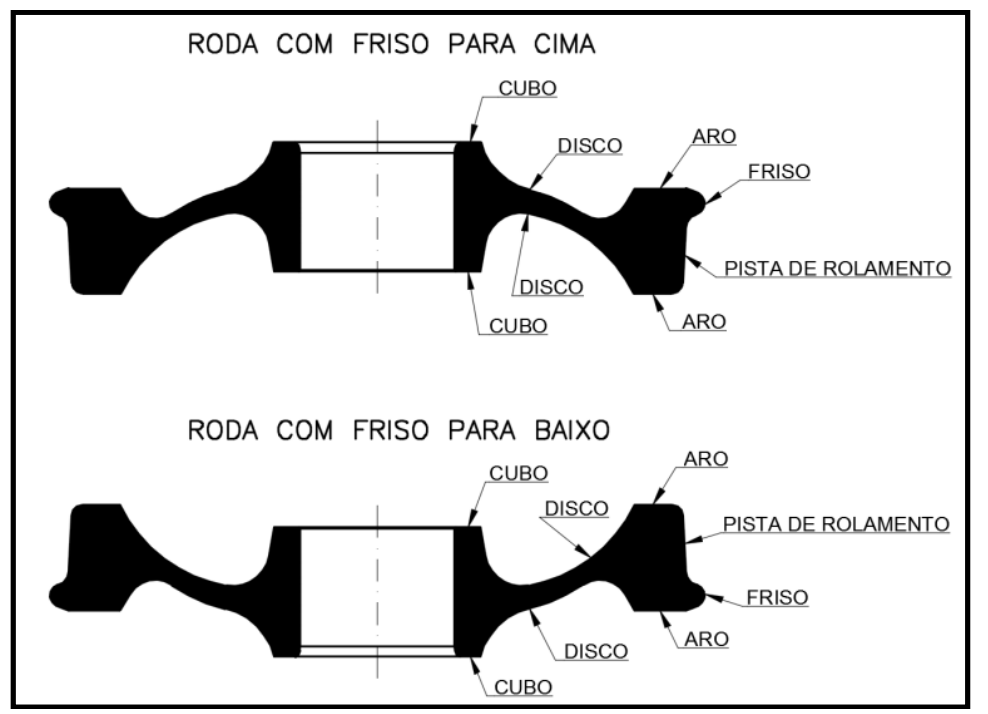

Figura 1. Terminologia de uma roda ferroviária

\section{REVISÃO DA LITERATURA}

De acordo com Niemann (2002), verifica-se que a maioria das dificuldades e erros de projetos são originada por exposição falha dos seus objetivos e por uma formulação incompleta dos problemas.

A metodologia para o projeto consiste na definição do problema, levantamento de dados, elaboração de hipóteses para o projeto, decisões preliminares do projeto, croquis, modelos matemáticos, viabilidade do projeto, protótipo, validação e aprovação, documentar fases e resultados (NORTON, 2014). 


\section{ISSN 2447-5378}

\subsection{Aspecto ergonômico e de segurança do trabalho}

Além de ser limitado pela posição do friso, existe risco do usuário sofrer algum acidente, pois o mesmo fica muito próximo da roda, demostrado na Figura 2 e para posicionar deve-se aplicar uma determinada força para abrir a garrincha e encachar na posição correta para depois iça-lo (BRASIL, 19).

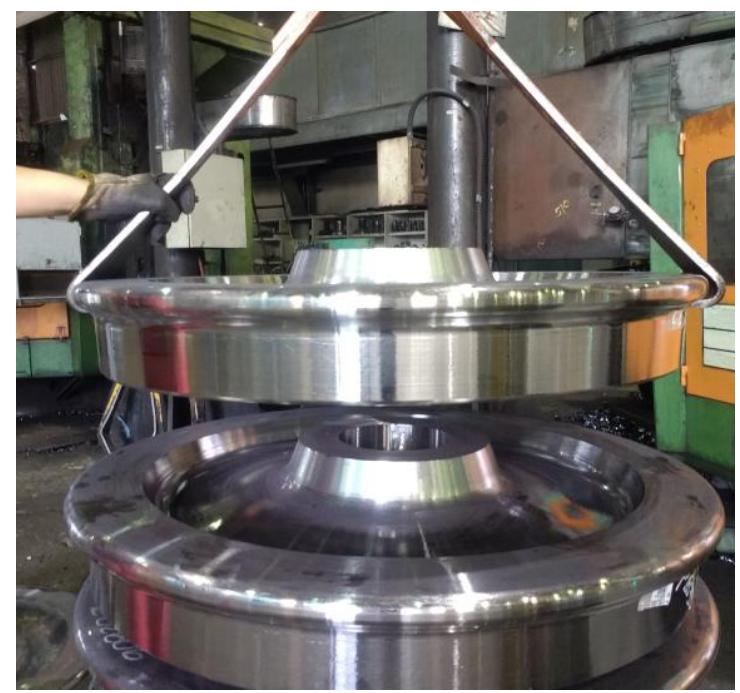

Figura 2. Garra para içar a roda com friso para cima

Através destas informações, elabora-se um sistema de fixação para realizar o travamento e içamento das rodas independente da posição do friso, geometria e peso (NIEMANN, 2002). Para desenvolver um sistema de fixação universal, primeiramente foi necessário entender as variações que podem ter em uma roda ferroviária, conforme Tabela 1.

Tabela 1. Dados dimensionais mínimo e máximo de uma roda ferroviária.

\begin{tabular}{lrr}
\hline \multicolumn{1}{c}{ Variável } & Mínimo & Máximo \\
\hline Diâmetro da pista de rolamento (mm) & 700.0 & 1200.0 \\
Diâmetro total da roda (topo do friso) (mm) & 740.0 & 1275.0 \\
Altura do friso (mm) & 20.0 & 37.5 \\
Largura do aro (mm) & 100.0 & 180.0 \\
Projeção do cubo (mm) & 0.0 & 75.0 \\
Altura total da roda com aro+projeção do cubo (mm) & 100.0 & 255.0 \\
Peso (kg) & 240.0 & 1270.0 \\
\hline
\end{tabular}

\subsection{Elaboração de hipóteses}

Através dos dados obtidos foi proposta uma garra com o mesmo sistema de pega já existente conforme Figura 3, sendo a área de contato entre a garra e a roda, porém com uma estrutura modificada, onde as variações de geometrias da roda que assegure a ação do mesmo. Na Figura 3, o esboço de uma garra usual na maior parte das indústrias para içamento. 


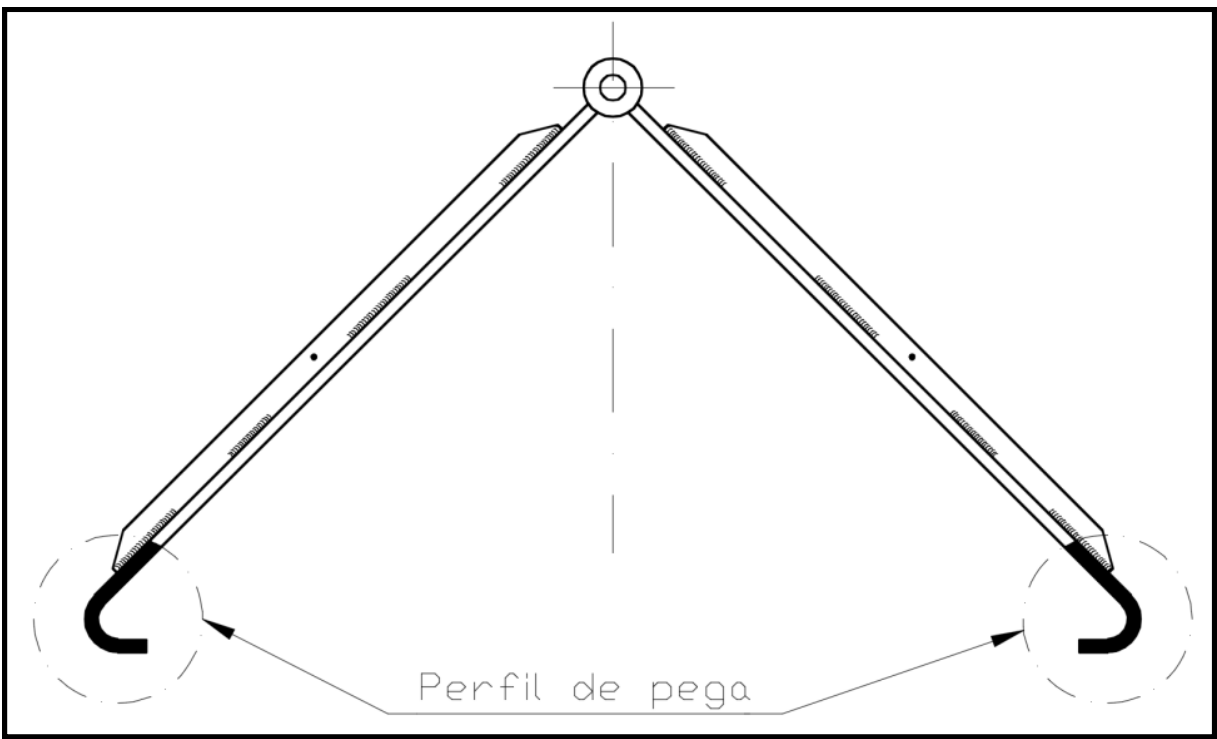

Figura 3. Garra convencional.

Conforme as NRs 11, e 17, são um requisito o transporte seguro. Na mesma linha, a ergonomia será desenvolvida uma haste articulada que será fixada em um lado da garra, que terá a função de distanciar o usuário da carga e ao mesmo tempo eliminar a força exercida para abrir a garra na abertura necessária para fazer o travamento da roda (BRASIL, 2019).

\subsection{Decisão preliminar do projeto}

As dimensões da garrincha (garra de fixação) foram definidas de acordo com o estudo realizado na Figura 4, sendo içadas as rodas em condições extremas, ou seja, nas dimensões máximas e mínimas de uma roda ferroviária (NIEMANN, 2002).

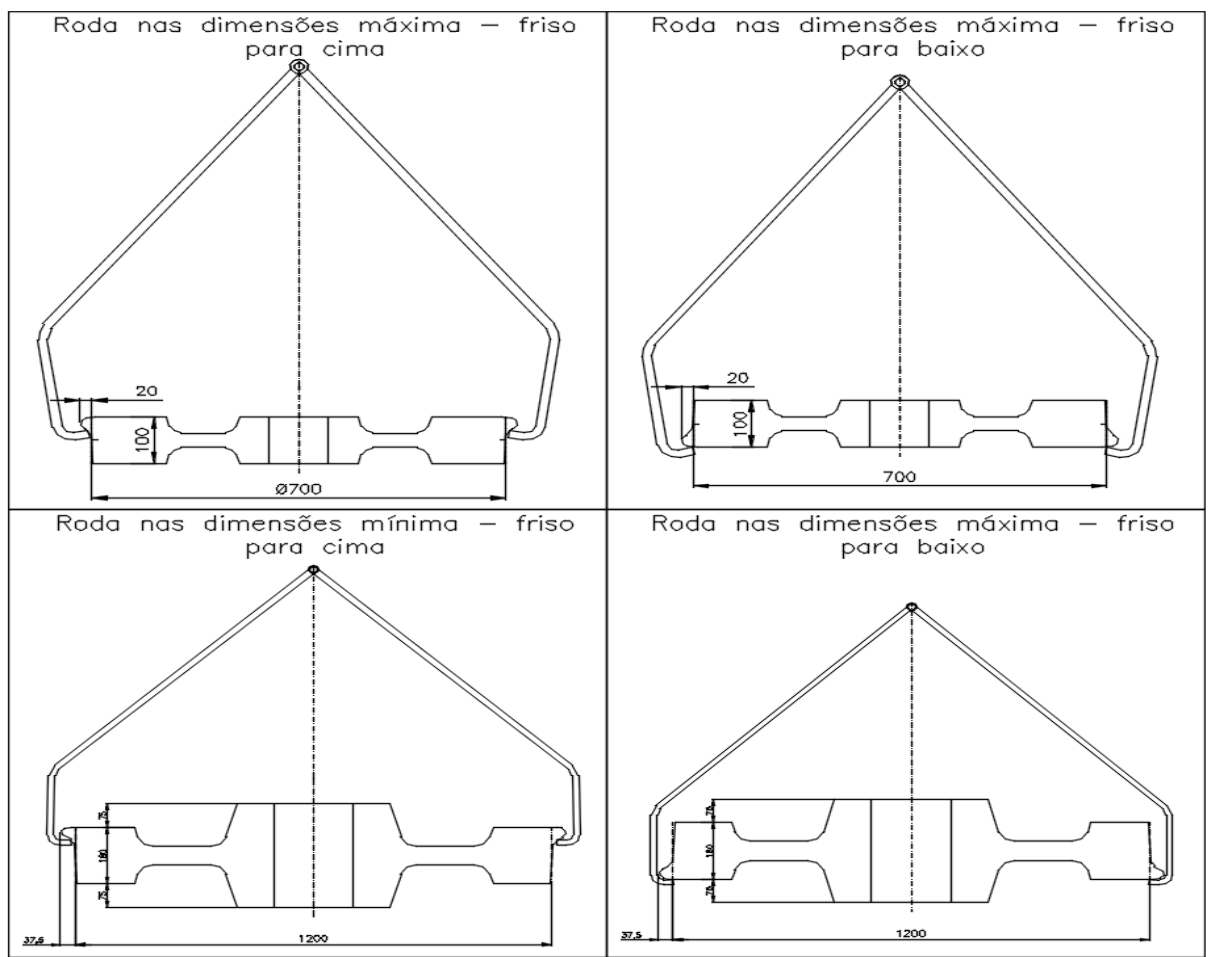

Figura 4. Estudo de fixação. 


\section{ISSN $2447-5378$}

Após concluir o método de içamento e geometria da garrincha que garantisse a fixação segura do produto e ergonomia para o usuário, foi realizado na Figura 5 o projeto preliminar do dispositivo ergonômico de içamento de roda ferroviária por sistema de fixação universal.

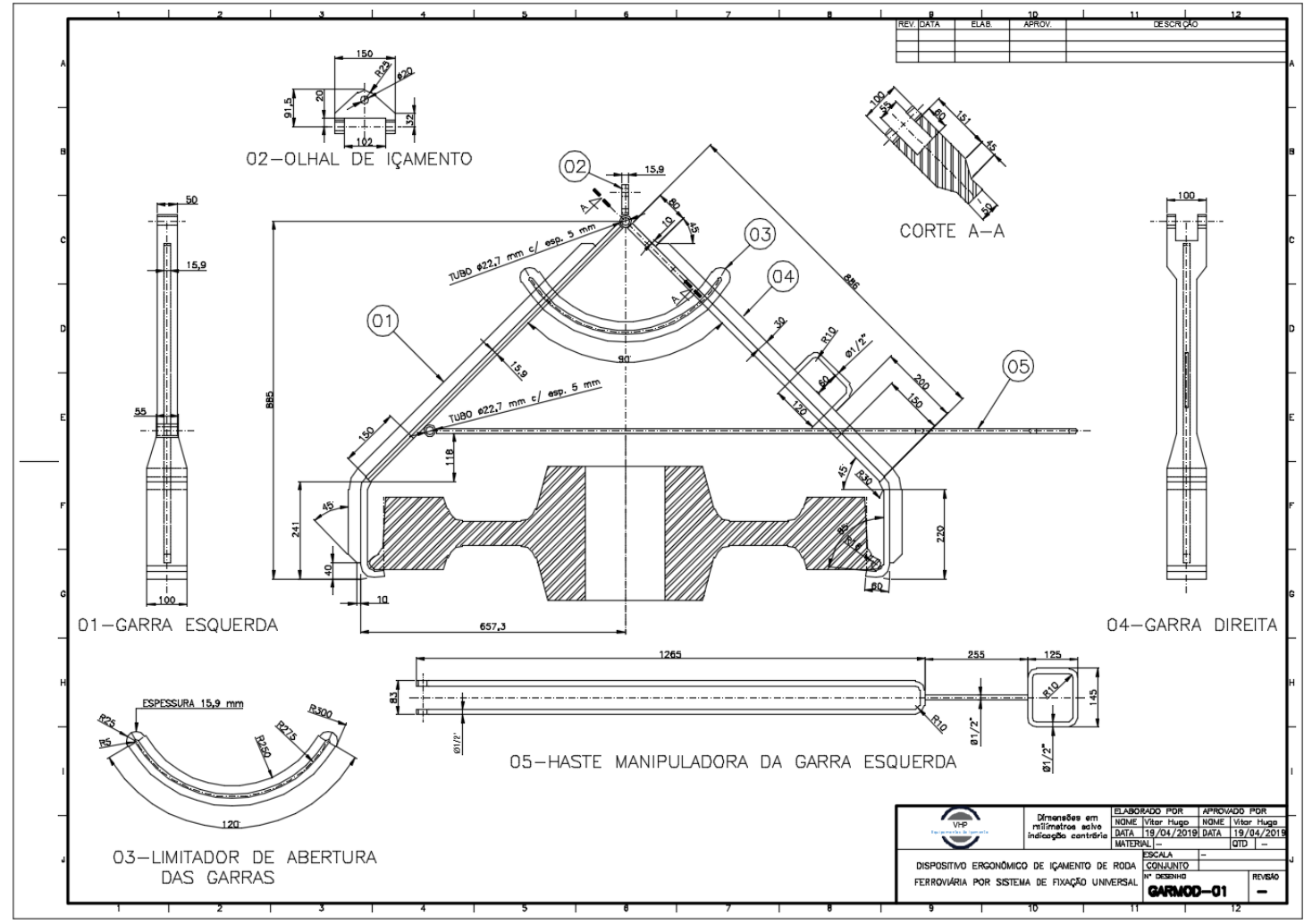

Figura 5. Desenho preliminar do dispositivo de fixação universal.

\section{MATERIAIS E MÉTODOS}

Para que a construção do equipamento seja realizada, é necessário prover os materiais para sua fabricação. É de vital importância a certificação dos materiais adquiridos quanto a sua conformidade com as características propostas para o material em específico, conforme Tabela 2.

Tabela 2. Composição química e propriedades mecânicas de materiais da garra.

\begin{tabular}{|c|c|c|c|c|c|c|c|c|c|c|c|}
\hline \multirow{3}{*}{$\begin{array}{l}\text { Faixa de espessura } \\
\qquad(\mathrm{mm})\end{array}$} & \multicolumn{6}{|c|}{ Composição Química (\% em massa) } & \multicolumn{5}{|c|}{ Propriedades Mecânicas } \\
\hline & \multirow[b]{2}{*}{ c } & \multirow[b]{2}{*}{$\mathrm{Si}$} & \multirow[b]{2}{*}{ Mn } & \multirow[b]{2}{*}{$\mathbf{P}$} & \multirow[b]{2}{*}{$\mathbf{S}$} & \multirow[b]{2}{*}{ Outros } & \multirow{2}{*}{$\begin{array}{c}\text { LE (Mpa) } \\
\quad Y P\end{array}$} & \multirow{2}{*}{$\begin{array}{c}\text { LR (Mpa) } \\
\text { TS }\end{array}$} & \multicolumn{3}{|c|}{ Alongamento } \\
\hline & & & & & & & & & \begin{tabular}{|c|}
$\begin{array}{c}\text { Espessura } \\
(\mathrm{mm})\end{array}$ \\
\end{tabular} & BM (mm) & $\%$ \\
\hline $6,00 \leq E 38,10$ & 0,25 máx. & 0,40 máx. & $080-120$ & \multirow{4}{*}{ 0,040 máx. } & \multirow{4}{*}{ 0,050 máx. } & \multirow{4}{*}{ (1) } & \multirow{4}{*}{$250 \mathrm{~min}}$. & \multirow{4}{*}{$400-550$} & \multirow{4}{*}{ (2) } & \multirow{4}{*}{200} & \\
\hline $38,11 \leq E 63,50$ & 0,26 máx. & \multirow{3}{*}{$0,15-0,40$} & & & & & & & & & 18 \\
\hline $63,51 \leq E 101,60$ & 0,27 máx. & & $085-120$ & & & & & & & & \\
\hline $101,61 \leq E 150,00$ & 0,29 máx. & & $0,0 J-1, \angle 0$ & & & & & & & & \\
\hline
\end{tabular}


Na Tabela 2, demonstra a composição química e suas propriedades mecânicas conforme cada faixa de espessura do material ASTM A36. Este material se enquadra entre os materiais da chamada estrutural, aços de médio ou alta resistência, adequados a finalidades estruturais, além de possuir excelente soldabilidade (LUZ, 2017).

\subsection{Analise estrutural por elementos finitos}

Foi utilizado o Software SolidWorks para os cálculos de elementos finitos e para esta análise estrutural considerou-se apenas os itens relevantes como estrutura metálica (garrincha) e o acessório de içamento (Olhal), haja vista que estes itens são sujeitos aos esforços presentes na utilização, e que necessitam da realização de cálculo de resistência por não serem itens comerciais, de fornecimento de terceiros, sendo ainda suas reações aos citados esforços desconhecidas.

\subsection{Condições de contorno}

As condições de contorno para o dispositivo carregado se encontram na Figura 6 e Figura 7 , onde as áreas de contato estão demarcadas em verde. Os deslocamentos estão travados, não permitindo translações em X, Y e Z, tanto no ponto de içamento, quanto nos pontos de contato com a roda, rotações foram permitidas, pois nem no içamento, nem no contato com a roda existe fixação além do atrito. Para esta análise, foi considerada uma abertura de $1200 \pm 20 \mathrm{~mm}$, valores de maior e menor abertura para o bom funcionamento do equipamento.

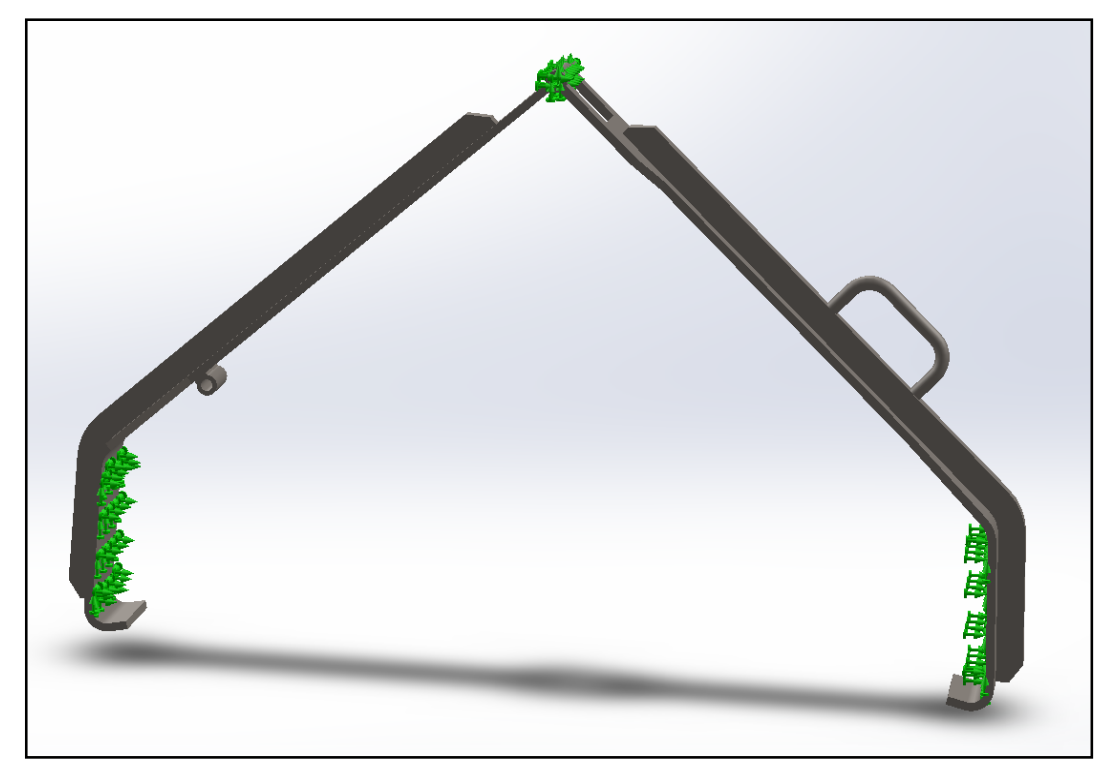

Figura 6. Condição de travamento das garras de fixação.

\subsection{Normas de segurança e qualidade para o projeto}

Norma regulamentadora $n^{\circ} 11$ - Transporte, Movimentação, Armazenagem e Manuseio de Materiais: é de extrema importância para dar os conceitos, obrigatoriedade e limites para o transporte seguro, armazenagem e ao manuseio de materiais, tanto de forma mecânica quanto manual (BRASIL, 2019).

Norma regulamentadora $\mathrm{n}^{\mathrm{o}} 12$ - Máquinas e Equipamentos: define as referências técnicas, princípios fundamentais e medidas de proteção para garantir a saúde e a integridade física dos trabalhadores e estabelece requisitos mínimos para a prevenção de acidentes e doenças do trabalho nas fases de projeto e de utilização de máquinas e equipamentos de todos os tipos, e ainda à sua fabricação, importação, comercialização, exposição e cessão a qualquer título, em todas as 


\section{ISSN $2447-5378$}

atividades econômicas, sem prejuízo da observância do disposto nas demais Normas Regulamentadoras (BRASIL, 2019).

Norma regulamentadora $\mathrm{n}^{\circ} 17$ - Ergonomia: visa a estabelecer parâmetros que permitam a adaptação das condições de trabalho às características psicofisiológicas dos trabalhadores, de modo a proporcionar um mínimo de conforto, segurança e desempenho eficiente (MOURA et al., 2018).

As condições de contorno para o olhal de içamento se encontram na Figura 7. Os deslocamentos estão travados, não permitindo translações, nem rotações em $\mathrm{X}, \mathrm{Y}$ e Z, considerando um caso crítico de travamento.

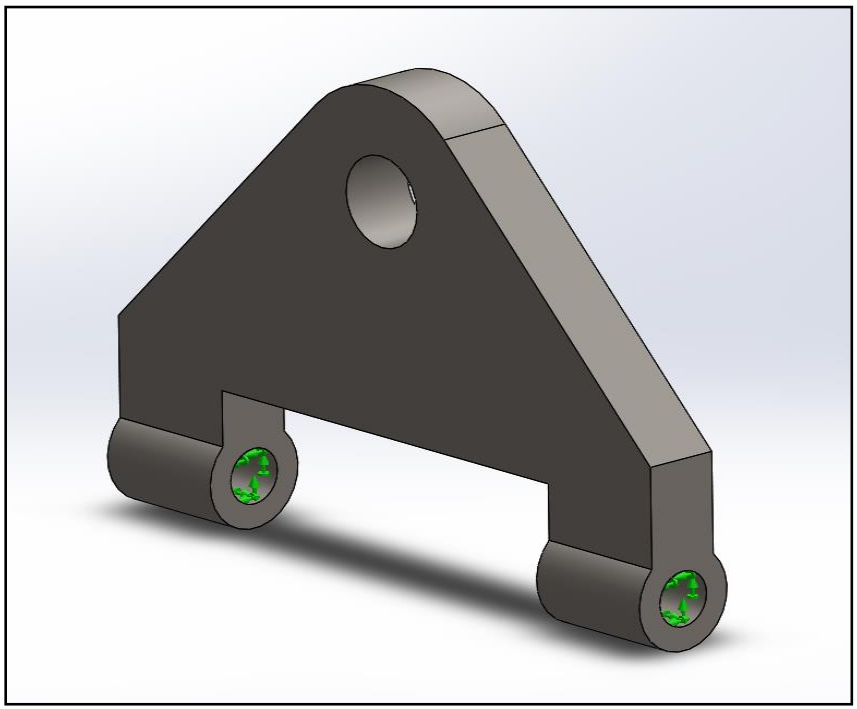

Figura 7. Condição de travamento do olhal de içamento

\subsection{Condições de carregamento}

O dispositivo é projetado para suportar cargas previstas conforme esquema de distribuição de cargas apresentado na Figura 8 e 9. O valor da carga aplicada está ligado a pior condição de utilização, ou seja, a uma força peso de $1.270,0 \pm 10 \mathrm{Kg}$.

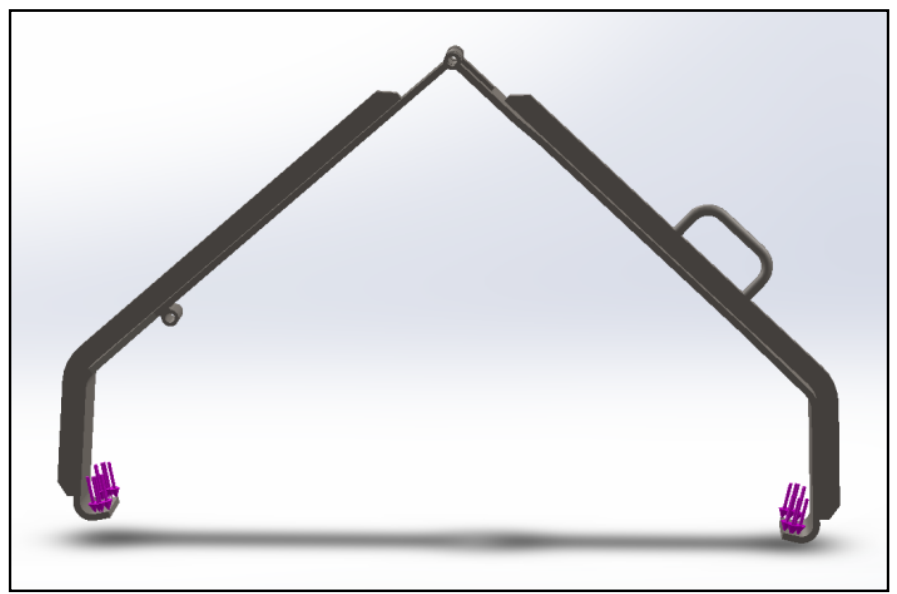

Figura 8. Aplicação de carga nas garras de fixação.

Na Figura 9 demostra a região e o sentido aonde sofrerá os esforços ao içar uma roda ferroviária. 


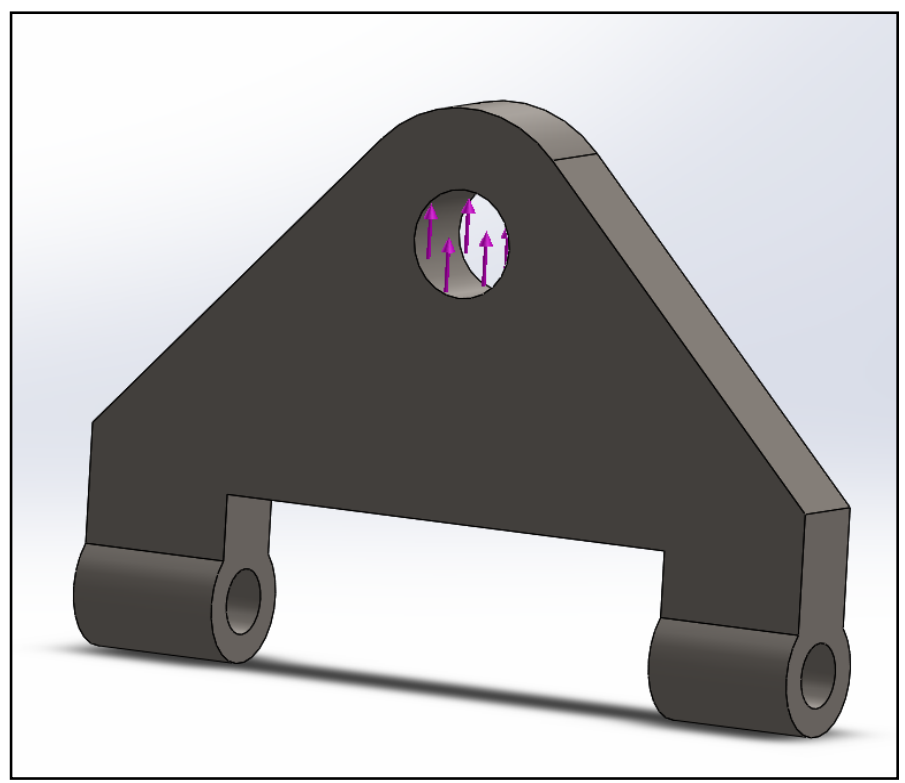

Figura 9. Aplicação de carga do olhal de içamento

\subsection{Análises de cargas e esforços}

Após definir tipo de material, as condições de contorno e carregamento do dispositivo no software SoliWorks, foi executado uma análise estrutural para entender seu comportamento, realizar possíveis melhorias e validação do equipamento. A Figura 10 demostra que ao aplicar a carga estabelecida no capitulo anterior, a garrincha sofre um deslocamento, ou seja, uma deformação de 0,1997 mm na região em vermelho, área de maior esforço.

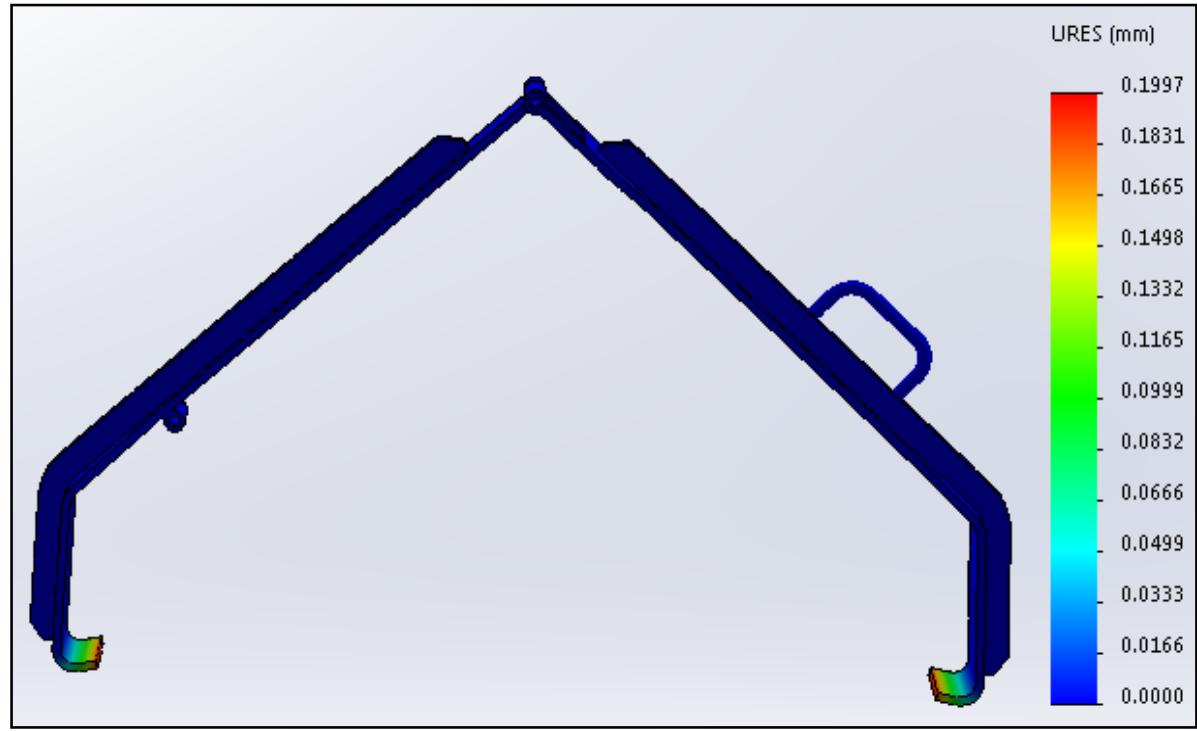

Figura 10. Deslocamento sofrido pela garra de fixação.

A Figura 11, informa a tensão combinada na estrutura através do critério de falha de Von Mises que indica que o escoamento do material sólido inicia quando o segundo invariante deviatório de tensão atinge um valor crítico.

$\mathrm{Na}$ garrincha embora a tensão tenha se apresentado com um valor de 154,7 Mpa, pode-se considerar que este pico de tensão, advém de uma pequena concentração de malha, e que não representa risco ao fator de segurança do dispositivo, uma vez que o entorno da garra está em escalas 


\section{ISSN $2447-5378$}

de cores em tons de amarelo e verde, representando uma tensão de aproximadamente $110 \mathrm{Mpa}$, inferior ao limite de escoamento do material que está por volta de $250 \mathrm{Mpa}$.

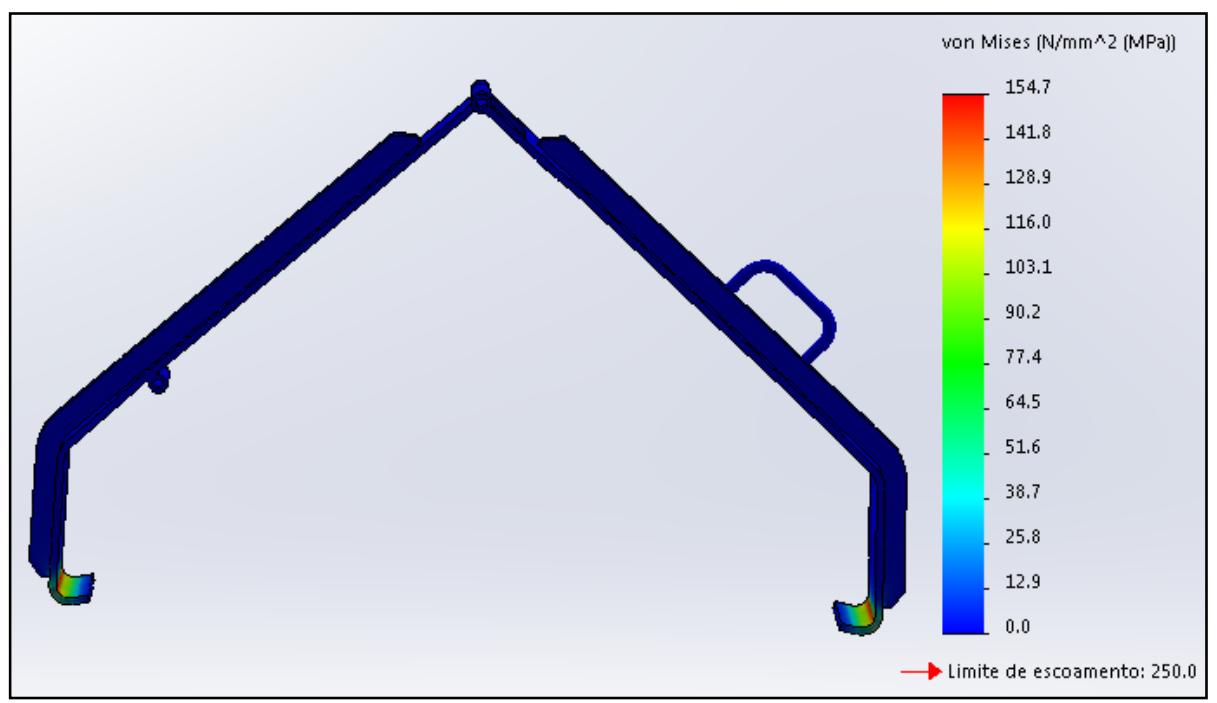

Figura 11. Tensão combinada na garra de fixação (Von Mises).

Para o olhal de içamento, foi realizado a análise estrutural nas mesmas condições da garrincha, conforme demostrado na Figura 12, onde resultou uma deformação de 0,0105 mm na região em vermelho, área de maior esforço.

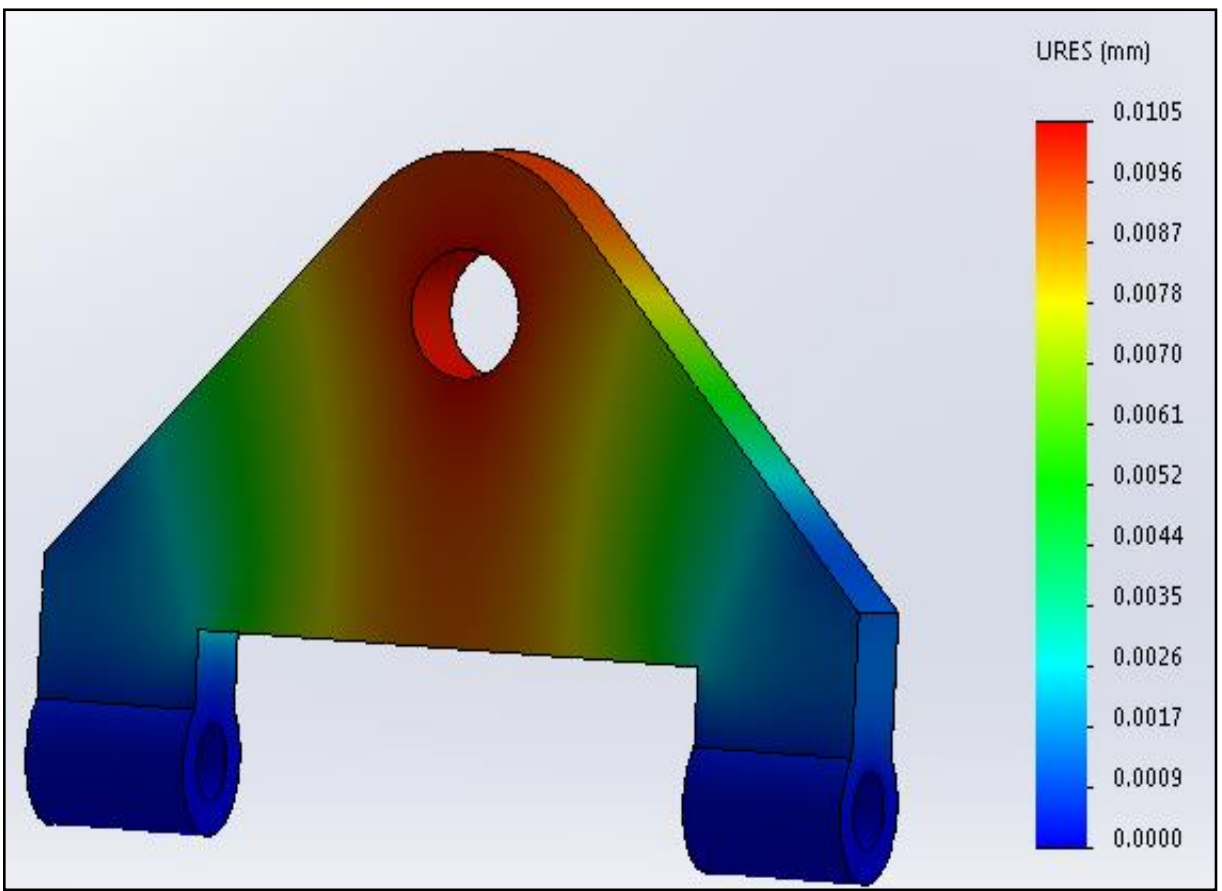

Figura 12. Deslocamento sofrido no olhal de içamento.

A tensão combinada no olhal de içamento demonstrada utilizando o critério de falha de Von Mises foi de 59,2 Mpa, inferior ao limite de escoamento do material.

\subsection{Imagem do produto}


Após protótipo com modelos matemáticos finalizados, foi feito um trabalho de renderização dos modelos de modo a ser possível constatar como teríamos as peças finais em sua entrega aos usuários, conforme Figura 13.

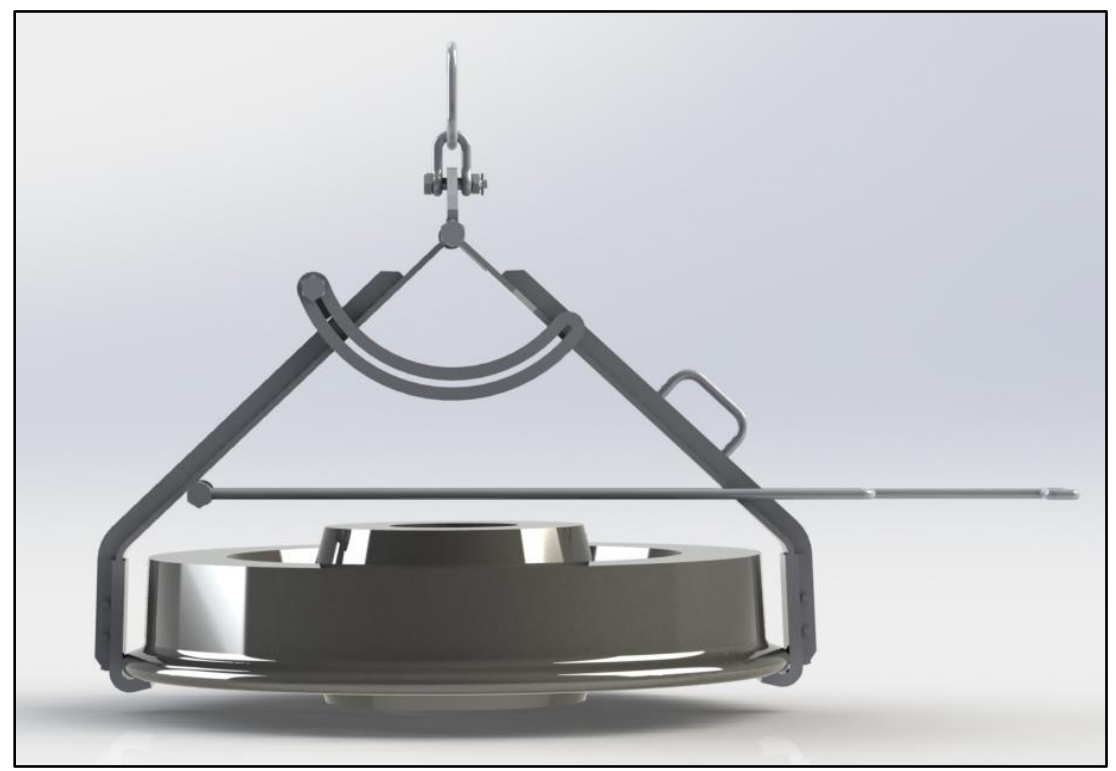

Figura 13. Imagem do dispositivo e transporte.

\section{RESULTADOS E DISCUSSÕES}

O resultado alcançado foi a resolução do problema apontado melhorando a segurança, ergonomia e atividade de transporte.

Para os operadores que foram ouvidos e algumas sugestões aceitas, melhorou a percepção por parte deles de que a atividade segura é a premissa da empresa.

Conclui-se que foi gerado um dispositivo ergonômico de içamento de roda ferroviária por sistema de fixação universal, podendo ser usado chapas de sacrifício em ambas às garras, para um menor custo de manutenção e acionamento com comando elétrico devidamente desenvolvido para a operação, reduzindo movimentos bruscos e esforços dos operadores.

\section{CONCLUSÃO}

Neste projeto buscou-se desenvolver um dispositivo tendo como ponto forte a robustez do equipamento, com alto fator de segurança para seus componentes e oportunidade futura de automatizá-la com içamento por robôs colaborativos.

Foi inserido no contexto de manutenção preventiva o ensaio não destrutivo de líquido penetrante e revelador, verificação da soldagem norma AWS D14.1 e limpeza mecânica, conforme prevê a legislação e instruções de segurança da norma ISO 8501-1ST3.

\section{REFERÊNCIAS}


BRASIL. Ministério do Trabalho e Emprego. Normas regulamentadoras. Disponível em: https://enit.trabalho.gov.br/portal/index.php/seguranca-e-saude-no-trabalho/sst-menu/sstnormatizacao?view=default. Acesso em: 19 de abril de 2019.

DEMIDOVER. História do Guindaste. 2010. Disponível em https://goingtoup.wordpress.com/2010/12/26/historia-dos-guindastes/. Acesso em 06 de abril de 2019.

LUZ, G. Materiais metálicos. 2017. Disponível em: https://www.materiais.gelsonluz.com/2017/10/astm-a36-propriedades-mecanicas-e-composicaoquimica.html. Acesso em: 19 de abril de 2019.

MOURA, R, A.; SANTOS, R, R.; SILVA, F. A. Ergonomia 4.0 como solução para o absenteísmo e para prevenção de lesões por esforços repetitivos e distúrbios osteomusculares no trabalho. $\mathrm{V}$ Congresso Internacional de Gestão e Tecnologia. 2018. FATEC São José dos Campos/SP. ISSN 2447-5378.

NAVARRO, A. F. "Acidentes causados durante a movimentação de cargas. Uma análise estatística dos acidentes". $2019 . \quad$ Disponível em: https://www.editoraroncarati.com.br/v2/phocadownload/artigos_e_estudos/Acidentes_Causados_D urante_a_Movimentacao_de_Cargas.pdf. Acesso em: 06 de abril de 2019.

NIEMAM, G. Elementos Máquinas, Volume I e 2 - Ed. Edgar Blusher, 2002.

NORTON, Robert L. Projeto de máquinas. Bookman Editora, 2014. 